\title{
Cyclophosphamide treatment of female non-obese diabetic mice causes enhanced expression of inducible nitric oxide synthase and interferon-gamma, but not of interleukin-4
}

\author{
H. Rothe", A. Faust", U. Schade, R. Kleemann, G. Bosse, T. Hibino, S. Martin, H. Kolb \\ Diabetes Research Institute at the Heinrich-Heine University, Düsseldorf, Germany
}

Summary In pancreatic lesions of non-obese diabetic (NOD) mice the expression of inducible nitric oxide synthase (iNOS) and of the cytokines interferongamma and interleukin-4 were studied. Strong iNOS expression as determined at the level of transcription, translation and of enzyme activity was associated with destructive insulitis as seen 8-10 days after cyclophosphamide treatment of 70 - to 80 -day-old female NOD mice. Immunohistochemistry showed iNOS associated with infiltrating macrophages but not in endocrine cells. The enhancement of iNOS after cyclophosphamide correlated with an increase of T-helper type 1 (Th1) associated interferon-gamma expression while T-helper type 2 (Th2) associated interleukin-4 was the dominant cytokine prior to cyclophosphamide and after diabetes onset. We conclude that insulitis in young NOD mice is carried by Th2 cells while cyclophosphamide enhanced insulitis is determined by Th1 cells. Macrophages show two different functional states in insulitis; strong iNOS expression in macrophages is associated with destructive insulitis. [Diabetologia (1994) 37: 1154-1158]

Key words Inducible NO synthase, NOD mice, cyclophosphamide, T-helper cell type 1, T-helper cell type 2.
In diabetes-prone non-obese diabetic (NOD) mice the loss of insulin-producing beta cells occurs in the context of lymphocytic and monocytic islet infiltration. Macrophages play an essential role in initiating insulitis: they are the first islet infiltrating cells, and immune intervention directed against macrophages prevents diabetes development [1]. Diabetes development can be accelerated and synchronised by cyclophosphamide (CY) in young NOD mice. In this

Received: 22 April 1994

and in revised form: 30 June 1994

Corresponding author: Dr. H. Rothe, Diabetes Research Institute, Auf'm Hennekamp 65, D-40225 Düsseldorf, Germany

Abbreviations: CY, Cyclophosphamide; FCS, fetal calf serum; iNOS, inducible NO synthase; NO, nitric oxide; NOD, nonobese diabetic; RT-PCR, reverse transcriptase polymerase chain reaction; TH1/2, T-helper type $1 / 2$.

* The contributions of H.Rothe and A. Faust to this paper should be considered as equal. model, macrophages were also shown to be critically involved [1].

Recently it has been found that after stimulation, macrophages express an inducible form of nitric oxide synthase (iNOS) and release large amounts of nitric oxide (NO). Inhibition of this enzyme suppresses the cytotoxicity of activated macrophages against islet cells in vitro [2]. Furthermore, chemically generated NO induced islet cell destruction in vitro [3]. A role of $\mathrm{NO}$ in beta-cell destruction in vivo is supported by the demonstration of enhanced NO production in NOD mouse islets [4]. Administration of an inhibitor of islet NO formation delayed the onset of diabetes after spleen cell transfer from diabetic female to non-diabetic male NOD mice [4]. The disease development in the NOD mouse is controversially discussed to be caused by either type 1 [5] or type 2 [6] helper T-cell mechanisms. The aim of our present study was to investigate the impact of CY acceleration of diabetes development on the Th1/Th2 balance in pancreatic lesions and to study a possible control of intra-islet NO production by Th1 vs Th 2 cells. 


\section{Materials and methods}

\section{Animals}

Female Balb/c/Han mice were obtained from the central animal facility at the Heinrich-Heine University of Düsseldorf. Female NOD/Bom mice were purchased from Bomholtgard Breeding Centre (Ry, Denmark) at 9 weeks of age and maintained in our animal facility under conventional conditions with standard diet and tap water ad libitum. All mice were killed under anaesthesia for pancreas analysis. Balb/c mice and untreated NOD mice were killed at the age of 70-80 days. A second group was treated with CY $(250 \mathrm{mg} / \mathrm{kg}$ i.p. $)$ at 70 days of age and killed 8 to 10 days later or after developing diabetes, which was diagnosed by daily urinary glucose analysis, confirmed by blood glucose determination. Animals were regarded as diabetic when blood glucose levels were shown to be above $16.7 \mathrm{mmol} / 1(300 \mathrm{mg} / \mathrm{dl})$ as determined by the hexokinase method.

\section{$m R N A$ analysis}

Total RNA was isolated from fresh pancreatic tissue by acid guanidinium thiocyanate-phenol-chloroform extraction. Detection of mRNA was performed by reverse transcriptase polymerase chain reaction (RT-PCR). For this purpose specific primers were used for iNOS [7], interferon (IFN)-gamma, interleukin (IL)-4 and G3PDH (Clontech Laboratories Inc., Palo Alto, Calif., USA) in both steps of reactions. After a total of 35 cycles the products were subjected to electrophoresis on a $2 \%$ agarose gel followed by hybridization with specific ${ }^{32} \mathrm{P}$ labelled probes binding at sites between the primer sequences. Quantification of the signals was done by measuring the ${ }^{32} \mathrm{P}$ stimulated luminescence (PSL) with a phosphorimager (Fujix BAF 1000; Raytest, Staubenhardt, Germany). Relative PSL of iNOS, IFN-gamma and $\Pi \mathrm{L}-4$ was calculated by normalization of the measured PSL to the strength of the G3PDH PSL (set as 1000).

\section{Immunohistochemistry}

Pancreata of six untreated and six CY-treated animals were snap-frozen in liquid nitrogen chilled isopentane and stored at $-80^{\circ} \mathrm{C}$. Immunohistochemistry was done on acetone-fixed cryostat sections. Buffers for IFN-gamma staining were supplemented with $0.05 \%$ saponine (Sigma, Deisenhofen, Germany). Monoclonal antibodies against murine IL-4 and IFNgamma were obtained from Pharmingen, clone BVD6-24G2 and clone R4-6A2 (San Diego, Calif., USA); the macrophagespecific antibody F4/80 was from Camon (Wiesbaden, Germany). The polyclonal rabbit anti-iNOS serum was a kind gift of Dr. C. Nathan (Cornell University, New York, N.J., USA) [7]. Irrelevant rat monoclonal antibody or rabbit polyclonal antibody (anti-human-chorionic gonadotropin, Dako, Hamburg, Germany) were used as negative controls.

\section{Nitrite production in cultured islets}

Islets were isolated from Balb/c and NOD mice by ductal injection of collagenase [Serva, Heidelberg, Germany, $1.5 \mathrm{mg}$ / $\mathrm{ml}, 0.37 \mathrm{U} / \mathrm{mg}$ in Hank's balanced salt solution (Gibco, Heidel-

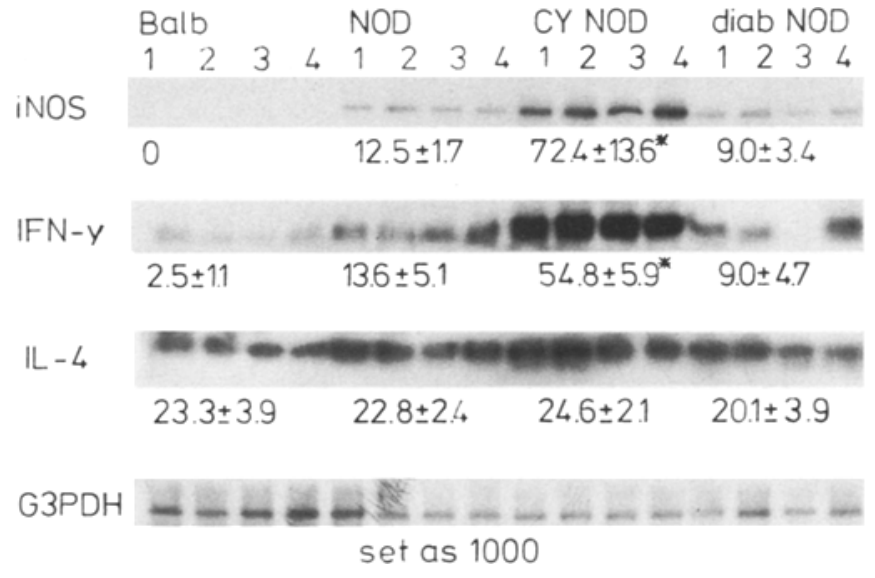

Fig. 1. RT-PCR analysis of pancreas mRNA of Balb/c mice, NOD mice, CY-treated NOD mice and diabetic NOD mice. Autoradiographs are shown of four individual animals per group after hybridization of the blotted RT-PCR products with ${ }^{32} \mathrm{P}$ labelled specific probes for iNOS, IFN-gamma, IL-4 and G3PDH. The radiolabel associated with PCR products of four animals per group was calculated by a phosphorimager. Balb/c mice and NOD mice were 70-80 days of age; CY NOD, NOD mice 8-10 days after treatment with CY; diab NOD, acutely-diabetic NOD mice after CY treatment. The relative quantity given is normalized to the G3PDH PCR product (set as 1000). Values are shown as mean $\pm \mathrm{SD}$. * significant differences between CY NOD and NOD

berg, Germany)] followed by density centrifugation on Ficoll gradient. Islets were cultured for $42 \mathrm{~h}$ in endotoxin-free RPMI 1640 (Gibco) supplemented with 10\% endotoxin-low FCS (Sigma). One hundred islets were cultivated in $200 \mathrm{ul}$ volume in 96-well round-bottom tissue culture plates. Supernatants were collected and NO production was detected by the Griess method [2]. $\mathrm{NO}_{2}^{-}$measurements were done in seven different experiments with two to four animals per group in each experiment. The detection limit of the $\mathrm{NO}_{2}-$ measurement was $0.5 \mathrm{nmol}$ per well.

\section{Statistical analysis}

Mean values were calculated and are presented with their standard deviation (SD). Mean radioactive signals of RT-PCR products were compared by Student's $t$-test.

\section{Results}

Using amplification of mRNA by RT-PCR the iNOS message was not detectable in pancreata of $\mathrm{Balb} / \mathrm{c}$ mice whereas weak signals could be detected in 70 to 80-day-old NOD mice. A strong induction of iNOS mRNA could be detected 8 to 10 days after a single injection of CY (Fig.1). Quantification of the signal intensities showed a sevenfold increase for iNOS mRNA after treatment with CY. In parallel, a significant fivefold increase for the Th1 type IFNgamma mRNA could be shown (Fig. 1). Acutely diabetic NOD mice showed a reduction in iNOS and 
IFN-gamma specific mRNA, reaching the levels of untreated NOD mice. On the other hand, the mRNA of the Th2 signal IL- 4 did not show any differences between Balb/c mice, 70- to 80-day-old NOD mice, CY-treated NOD mice or acutely diabetic NOD mice. Interestingly, the Th2 signal IL-4 in untreated NOD mice appears to be more strongly expressed than Th1 type signal IFN-gamma (Fig.1).

In immunohistochemistry inflamed islets of CYtreated NOD mice showed intensive staining for iNOS and IFN-gamma (Fig. 2B and F). In serial sections detection of iNOS corresponded to the presence of F4/80 macrophages (Fig. 2B and D). An expression of iNOS in endocrine cell areas was not detectable. In islets of 70- to 80-day-old untreated NOD mice, only very weak staining for iNOS could be observed in infiltrated islets, as well as in islets with massive accumulation of $\mathrm{F} 4 / 80$ positive macrophages (Fig. $2 \mathrm{~A}$ and C). Infiltrated islets of CY-treated NOD mice stained strongly for IFN-gamma (65 of 65 islets), while insulitis of untreated animals was rarely associated with this Th1 cytokine ( 4 of 48 islets) (Fig. $2 \mathrm{E}$ and F). In contrast to IFN-gamma, the Th2 type cytokine IL-4 was detected by immunohistochemistry in all infiltrated islets of untreated NOD mice (Fig. 2G). The intensity of IL-4 staining did not change after treatment of mice with CY (Fig. $2 \mathrm{H}$ ). In $\mathrm{Balb} / \mathrm{c}$ mice we also found IL-4 expression; staining was dispersed in the periphery of ducts, vessels and pancreatic septs (data not shown). Concomitant with elevated expression of iNOS, detected at the mRNA and protein level, isolated islets from CY-treated NOD mice showed increased production of $\mathrm{NO}_{2}{ }^{-}$in supernatants $(3.75 \pm 2.89 \mathrm{nmol}$ nitrite/100 islets) in comparison to untreated NOD mice (1.97 \pm $0.86 \mathrm{nmol}$ nitrite $/ 100$ islets) and $\mathrm{Balb} / \mathrm{c}$ mice $(0.68 \pm 0.63 \mathrm{nmol}$ nitrite $/ 100$ islets $) . \mathrm{NO}_{2}^{-}$release of CY-treated NOD mice showed great variation between individual measurements with 6 of $8 \mathrm{NO}_{2}^{-}$levels above the mean value of untreated NOD mice. Control experiments of these cultured islets showed also upregulated iNOS gene expression in islets of CY-treated NOD mice in contrast to lower expression in untreated NOD mice by RT-PCR (data not shown). Nitrite production in islets from untreated NOD mice was higher than in $\mathrm{Balb} / \mathrm{c}$ islets, with 6 of $7 \mathrm{NO}_{2}^{-}$levels above the mean of $\mathrm{Balb} / \mathrm{c}$. The variation in all $\mathrm{NO}_{2}{ }^{-}$release from NOD mouse islets, especially after treatment with $\mathrm{CY}$, is probably accounted for by a variable loss of infiltrating immune cells from the islets during isolation procedure.

\section{Discussion}

This study analyses the association of iNOS gene expression in pancreatic lesions of NOD mice in early and late stages of disease and with the functional state of helper T cells as determined by IFN-gamma and IL-4 gene expression. The expression of iNOS was determined at the level of transcription and enzyme activity. Furthermore, the protein was detected by immunohistochemistry on pancreatic sections. The data demonstrate slightly elevated levels of iNOS expression in the NOD mouse pancreas during early stages of the disease and a major increase when diabetes development was accelerated by a single CY injection. Also, a strong staining of iNOS protein could be observed, mainly in the islets of CYtreated animals. After diabetes onset downregulation of iNOS gene expression was seen. Thus, iNOS expression appears to correlate well with the intensity of beta-cell destruction which is low in 70- to 80day-old NOD mice, but strongly enhanced after CY treatment as demonstrated by significant increase of islets with infiltration [8] and rapid diabetes development. A possible role of iNOS in beta-cell destruction is supported by our earlier finding that activated macrophages lyse islet cells in vitro via iNOS-dependent NO formation [2]. The immunohistochemical studies showed colocalization of iNOS and the macrophage marker $\mathrm{F} 4 / 80$ while no staining was observed in areas of endocrine tissue. These observations do not favour the assumption that beta cells represent the major site of iNOS expression during diabetes development [9].

It is of interest that the kinetics of iNOS expression closely correlated with those of IFN-gamma expression, both at the mRNA and protein level. The upregulation of IFN-gamma after CY treatment is consistent with an earlier observation of Campbell et al. [10]. After diabetes onset IFN-gamma expression is reduced in parallel to the iNOS expression gene which implies that iNOS expression in macrophages is primarily induced by IFN-gamma-producing Th1 cells.

When extending our study to IL-4-producing Th2 cells we found that insulitis in earlier stages of disease development is characterized by a predominance of Th2 cells. While CY treatment favours Th1 activity and shifts the balance from Th2 to Th1 predominance with regard to cytokine gene expression there is surprisingly no reduction in the extent of IL4 mRNA or IL-4 antibody staining of insulitis regions. Thus, we do not find evidence for an antagonism of Th1 and Th2 cells. Rather, IL-4-producing

Fig. 2. Paired photomicrographs of immunohistochemistry of pancreas cryostat sections showing in the left panel $(\mathrm{A}, \mathrm{C}, \mathrm{E}$, $\mathrm{G})$ untreated NOD mice and in the right panel (B, D, F, H) NOD mice 10 days after CY treatment. Primary antibodies directed to iNOS $(A, B), F 4 / 80(C, D)$, IFN-gamma $(E, F)$ and IL-4 $(\mathrm{G}, \mathrm{H})$ were used. Original magnification was $1: 400(\mathrm{~A}$, $\mathrm{C}, \mathrm{E}, \mathrm{F}, \mathrm{G}, \mathrm{H})$ or $1: 250(\mathrm{~B}, \mathrm{D})$ 
NOD

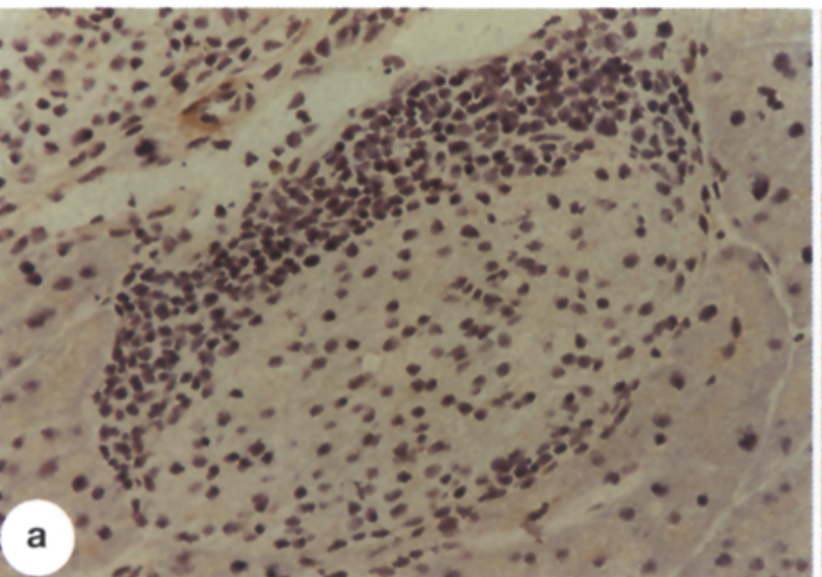

IFN

gamma
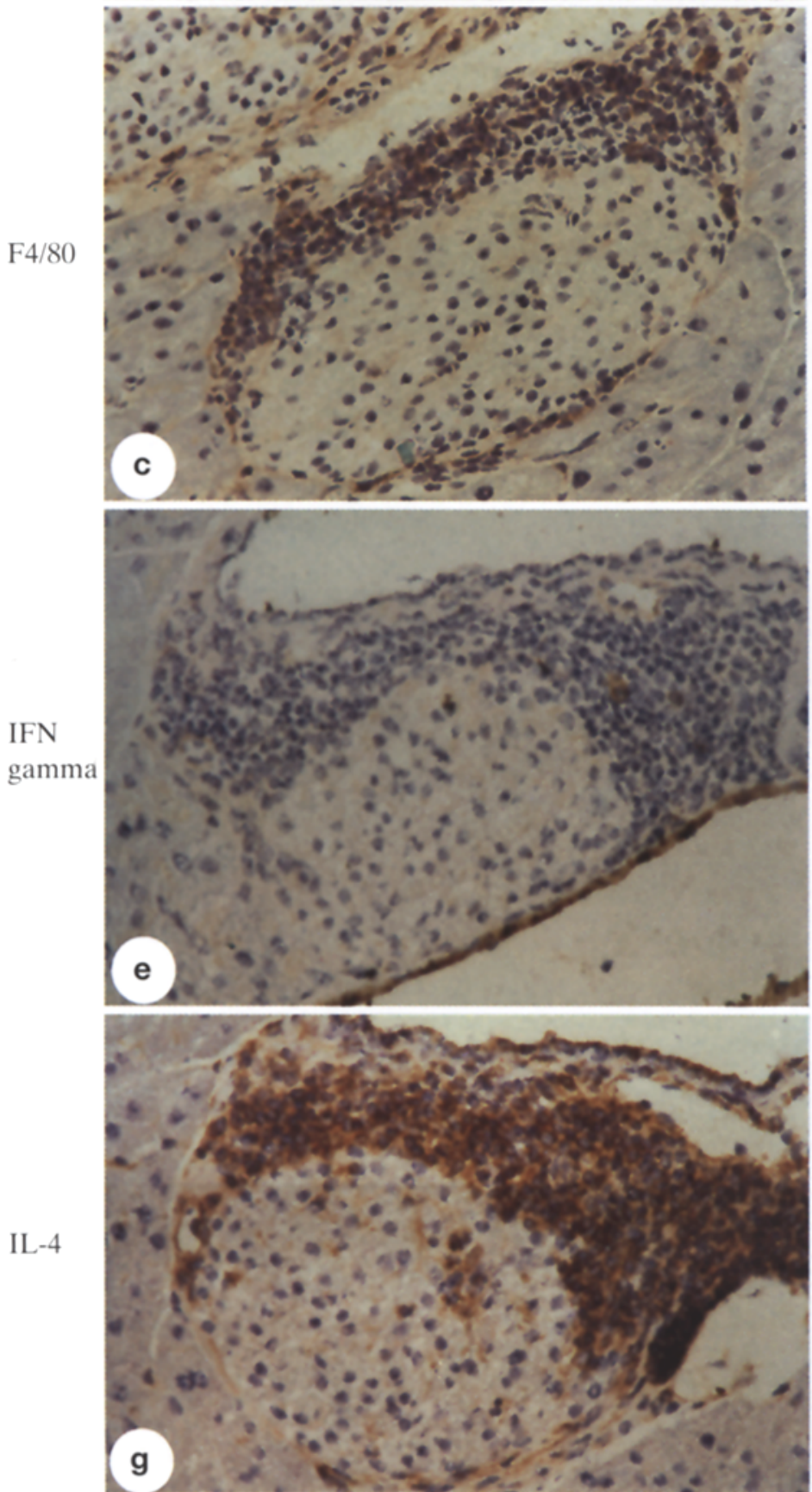

CY-treated NOD

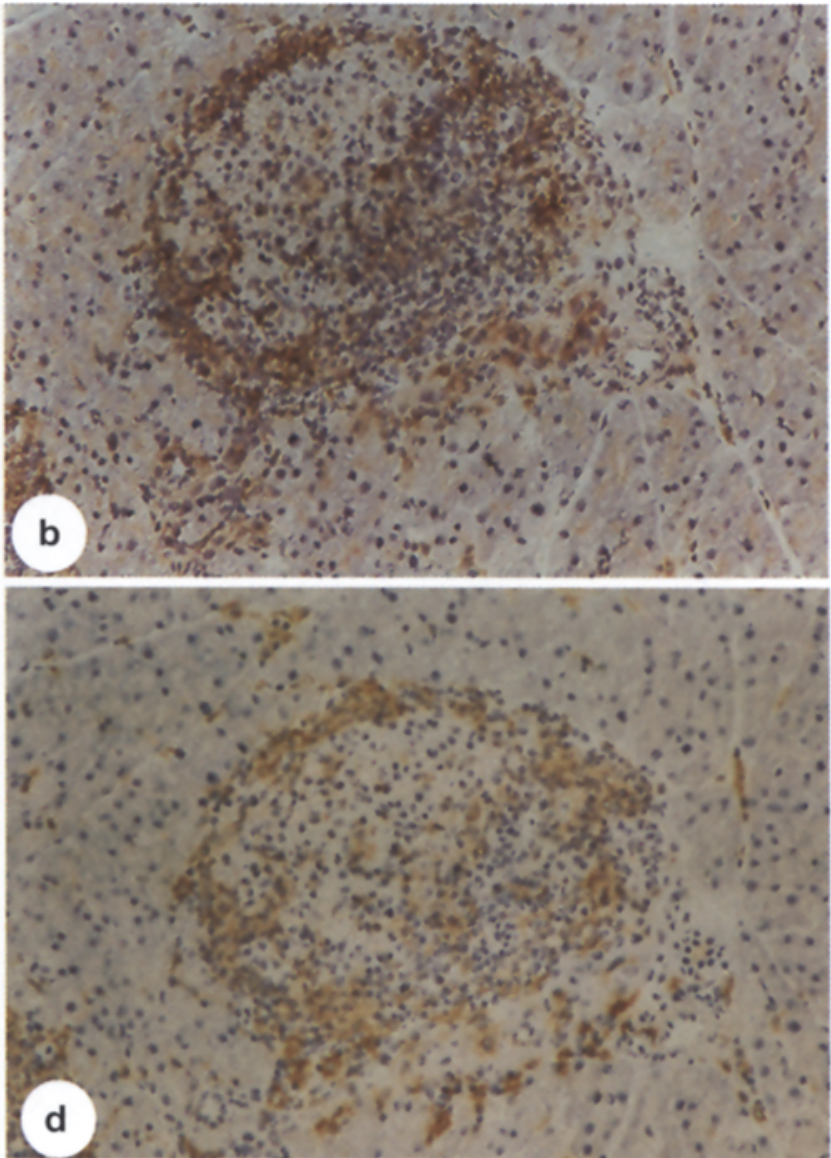

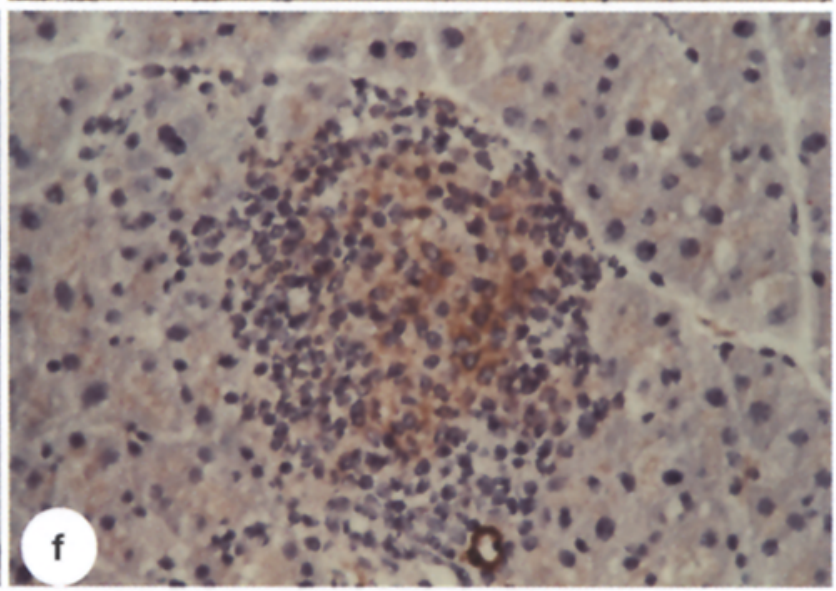

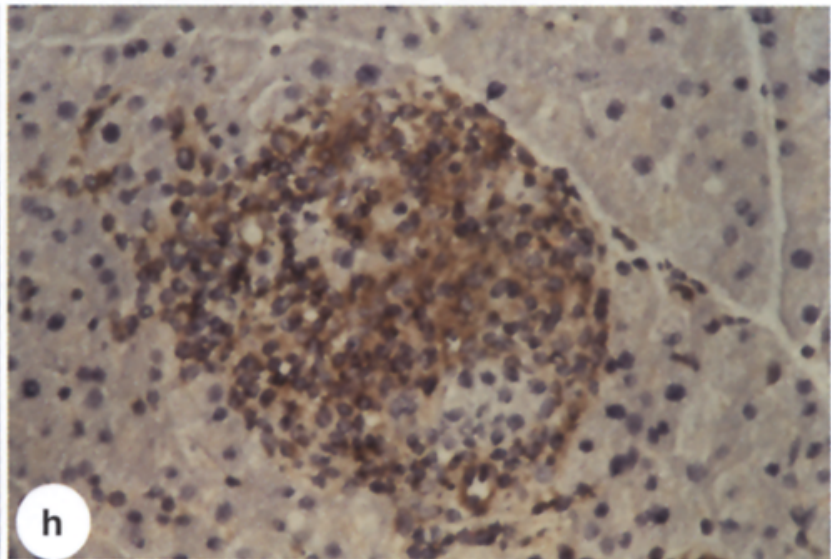


$T$ cells represent a continuous and major fraction of the islet infiltrate. The rapidity and aggressiveness of beta-cell destruction after CY treatment, however, appears to be controlled by IFN-gamma-producing T cells.

These findings contribute to resolving the controvers about the importance of Th1 vs Th2 cells in diabetes development. Anderson et al. [6] reported a dominance of Th2 cells among leucocytes isolated from infiltrated islets. Staining of islet sections, as done here, offers direct proof for a predominance of Th2 over Th1 cells in untreated NOD mice. Shehadeh et al. [5] reported that islet graft rejection in NOD mice correlates with a predominance if IFNgamma-positive T cells. Islet graft rejection is a process comparable to CY-accelerated diabetes development with regard to rapidity and synchronization. In such a situation we indeed observed a rise of Th1 cells in the islet infiltrate.

In conclusion, we find a dominance of Th2 cells during early stages of disease development and a shift to Th1 cells during accelerated destructive insulitis. Furthermore, we show two functional states of macrophages in NOD mouse insulitis, differing in the extent of iNOS gene expression. The close correlation of iNOS expression and IFN-gamma expression with diabetes development suggest a contribution of intra-islet NO production to beta-cell destruction.

Acknowledgements. We thank M. Blendow and R.Schmitt for excellent technical assistance. This work was supported by the Deutsche Forschungsgemeinschaft, the Bundesminister für Gesundheit, für Forschung und Technologie, the Minister für Wissenschaft und Forschung des Landes Nordrhein-Westfalen, the Juvenile Diabetes Foundation International and the Fritz Thyssen-Stiftung.

\section{References}

1. Lee K-U, Amano K, Yoon J-W (1988) Evidence for initial involvement of macrophages in development of insulitis in NOD mice. Diabetes 37: 989-991

2. Kröncke K-D, Kolb-Bachofen V, Berschick B, Burkart V, Kolb H (1992) Activated macrophages kill pancreatic syngenic islet cells via arginine-dependent nitric oxide generation. Biochem Biophys Res Commun 175: 752-758

3. Kallmann B, Burkart V, Kröncke K-D, Kolb-Bachofen V, Kolb H (1992) Toxicity of chemically generated nitrite oxide towards pancreatic islet cells can be prevented by nicotinamide. Life Sci 51: 671-678

4. Corbett JA, Anwar M, Shimizu J et al. (1993) Nitric oxide production in islets from nonobese diabetic mice: aminoguanidine-sensitive and -resistant stages in the immunological diabetic process. Proc Natl Acad Sci USA 90: 89928995

5. Shehadeh NN, LaRosa F, Lafferty KJ (1993) Altered cytokine activity in adjuvant inhibition of autoimmune diabetes. J Autoimmun 6: 291-300

6. Anderson JT, Cornelius JG, Jarpe AJ, Winter WE, Peck AB (1993) Insulin-dependent diabetes in the NOD mouse model II $\beta$ cell destruction in autoimmune diabetes is a Th2 and not a Th1 mediated event. Autoimmunity 15: $113-122$

7. Kleemann R, Rothe H, Kolb-Bachofen V, Xie Q-W, Nathan C, Martin S, Kolb H (1993) Transcription and translation of inducible nitric oxide synthase in the pancreas of prediabetic BB rats. FEBS Lett 328: 9-12

8. Faust A, Burkart V, Ulrich H, Weischer CH, Kolb H (1994) Effect of lipoic acid on cyclophosphamide-induced diabetes and insulitis in non-obese diabetic mice. Int J Immunopharmac 16: 61-66

9. Mandrup-Poulsen T, Corbett JA, McDaniel ML, Nerup J (1993) What are the types and cellular sources of free radicals in the pathogenesis of type 1 (insulin-dependent) diabetes mellitus? Diabetologia 36: 470-471

10. Campbell IL, Kay TWH, Oxbrow L, Harrison LC (1991) Essential role for interferon-gamma and interleukin-6 in autoimmune insulin-dependent diabetes in NOD/Wehi mice. J Clin Invest 87: 739-742 